\title{
A PERCEPÇÃO DOS GESTORES DE ESPORTE SOBRE JOGOS ESCOLARES BRASILEIROS
}

\author{
Andre Almeida Cunha Arantes \\ Universidade Católica de Brasília, Brasília, Distrito Federal, Brasil. \\ Francisco Martins da Silva \\ Universidade Federal da Paraíba, João Pessoa, Paraíba, Brasil. \\ José Pedro Sarmento Rebocho Lopes \\ Universidade do Porto, Porto, Portugal. \\ Gonzalo Bravo \\ West Virginia University, Virginia, Estados Unidos. \\ Gislane Ferreira de Melo \\ Universidade Católica de Brasília, Brasília, Distrito Federal, Brasil.
}

\section{Resumo}

Este estudo teve como objetivo investigar a percepção de gestores de esporte sobre os Jogos Escolares Brasileiros. Foram realizadas entrevistas semiestruturadas. A análise e interpretação dos dados revelaram que um princípio estruturante que guiou os Jogos foi a identificação e seleção de talentos esportivos. Quanto ao papel dos atores, os gestores observaram conflito entre as Secretarias de Educação e Secretarias de Esporte sobre a governança dos Jogos. Em termos de financiamento, os gestores constataram que os recursos sempre foram públicos. Em termos de perspectivas futuras, os gestores consideram a governança dos Jogos como atribuição dos Ministérios de Esportes e Educação.

Palavras-Chave: Organização e Administração. Política Pública. Educação. Educação Física e Treinamento.

\section{SPORTS MANAGERS' PERCEPTION OF THE BRAZILIAN SCHOOL GAMES}

\begin{abstract}
This study had the objective of investigate the perception of sports managers about the Brazilian School Games. Semi-structured interviews were conducted. Analysis and interpretation of data revealed that one structuring principle that guided the Games was talent selection and identification of athletes. Regarding the role of agents, managers noted the conflict of ownership between the Education Secretariat and Sports Secretariat concerning the responsibility of the Games. In terms of financing, managers noted that public resources fund these Games over the years. In terms of the future perspectives, managers noted that the governance of the Games should rest in the Ministries of Sports and Education.
\end{abstract}

Keywords: Organization and Administration. Public Policy. Education. Physical Education and Training. 


\title{
LA PERCEPCIÓN DE LOS GESTORES DE DEPORTES SOBRE LOS JUEGOS ES- COLARES BRASILEÑOS
}

\begin{abstract}
Resumen
Este estudio tuvo como objetivo investigar la percepción de gestores de deportes sobre los Juegos Escolares Brasileños. Se realizaron entrevistas semi estructuradas. El análisis e interpretación de los datos reveló que un principio estructurante que guió los juegos fue la identificación y selección de talentos deportivos. En cuanto al papel de los actores, los gestores observaron conflicto entre las Secretarías de Educación y Secretarias de Deporte sobre la gobernanza de los Juegos. En financiación, los gestores constataron que los recursos siempre fueron públicos. En cuanto perspectivas futuras, los gestores consideran que la gobernanza de los juegos debe ser atribución de los Ministerios de Deportes y Educación.
\end{abstract}

Palabras-Clave: Organización y Administración. Política Pública. Educación. Educación y Entrenamiento Físico.

\section{Introdução}

Os gestores são fundamentais nos espaços de decisão das organizações (MINTZBERG, 1990) e, nos poucos documentos encontrados durante a pesquisa, praticamente não há referência ao papel desempenhado por eles nos Jogos Escolares Brasileiros. Dentre os trabalhos que tratam do tema foram encontrados os de Thompson et al. (2005), Borges e Buoricone (2007), Tubino (2010), Arantes et al. (2012), Barbieri (1999), Oliveira (2011), Frizzo (2013), Gruppi, (2016) e Kiouranis (2017).

A originalidade deste trabalho consiste em abordar as quatro fases dos jogos escolares, desde sua criação em 1969 até 2010, e buscar os gestores de esporte que exerceram posição estratégica no desenvolvimento dos jogos em cada uma das quatro fases, a primeira entre 1969 e 1984, durante o período da ditadura civil militar, a segunda de 1985 a 1989, no período de redemocratização, a terceira de 1990 a 2004, no período pós-constituinte, e a quarta fase entre 2005 e 2010, no período de governo popular. Este estudo teve como objetivo investigar a perspectiva de gestores de esporte sobre os Jogos Escolares Brasileiros no período de 1969 a 2010.

\section{Material e métodos}

Este é um estudo qualitativo, de natureza exploratória, que utilizou como instrumento uma entrevista semiestruturada, em função da característica do grupo entrevistado, formado por especialistas altamente qualificados. Segundo Trivinos (1987, p. 146), a entrevista semiestruturada é adequada para esse público, pois sugere que "o informante, seguindo espontaneamente a linha de seu pensamento e de suas experiências dentro do foco principal colocado pelo investigador, começa a participar na elaboração do conteúdo da pesquisa”, oferecendo contribuição de qualidade ao desenvolvimento desse processo.

Foram selecionados dois gestores que atuaram no núcleo estratégico de decisão dos Jogos em cada fase e formou-se um grupo composto por um Ministro do Esporte, três Secretários Nacionais de Esporte e quatro Coordenadores Gerais dos Jogos. As oito entrevistas tiveram duração média de 50 minutos, com variação entre 28 e 98 minutos. As entrevistas foram realizadas com um gravador digital da marca OLYMPUS, modelo Digital Voice Recorder VN-3100PC e, posteriormente, foram transcritas em formato de texto.

Optou-se pela análise de conteúdo, por ser esta "um conjunto de técnicas de análise das comunicações" (BARDIN, 1994, p. 27), que possibilita buscar o oculto no relato dos ges- 
tores de esporte entrevistados. Ghiglione e Matalon (2005) acreditam que, no caso da análise de conteúdo das entrevistas, a questão prioritária é o discurso de cada um dos entrevistados, revelando o que existe de semelhanças e diferenças e como efetivamente pode ser organizado para que tenha fácil interpretação. Foi definido um sistema composto por quatro categorias: princípios estruturantes, papel dos atores, financiamento e perspectivas futuras.

\section{Resultados, análise e discussão}

\section{Princípios estruturantes}

Ao longo dos anos de existência, os Jogos foram marcados por descontinuidades que refletiram a falta de uma política única para sua organização e realização, fato observado na opinião dos gestores responsáveis pelos Jogos nas diferentes fases de realização. Da percepção dos gestores da primeira e da segunda fase emergem visões conflitantes. Os gestores da primeira fase (1969-1984) enfatizam o "fazer atletas", a preparação para os futuros atletas olímpicos, como se observa nas citações abaixo:

\section{CG-1 1 : "Nós não estamos querendo fazer atletas para o futuro? Então eu vou botar provas olímpicas". \\ SNE-12: "A preparação para os atletas darem passos maiores".}

Já os gestores da segunda fase (1985-1989) têm um conceito oposto, ou seja, de que os Jogos devem servir a um propósito educacional e não para a formação de atletas. Com essa "justificativa", decidem proibir os melhores atletas brasileiros da faixa etária inferior a 18 anos (atletas federados) de participar dos Jogos, como se vê abaixo:

CGa-2 ${ }^{3}$ : “O Bruno proibiu os federados, nos JEB's..."

CGb-2 ${ }^{4}$ : "Em alguns anos foi proibida a participação do atleta federado. Significou você fazer a ruptura com o Esporte de Rendimento. Romper com Esporte de Rendimento".

Os discursos de CG-1 e de SNE-1 são a respeito da busca de talentos por meio dos Jogos e encontra apoio em Grix (2012), quando este apresenta a Espartakiades como importante instrumento de detecção de atletas na Alemanha Oriental. De Bosscher (2009), na apresentação dos Nove Pilares para o Desenvolvimento Esportivo, destaca o papel da identificação de talento e das competições escolares para a estruturação do sistema de Esporte de Rendimento. O relatório do TCU (2011) aponta a necessidade de promoção de um sistema de detecção de talentos esportivos no Brasil e considera preocupante a baixa participação dos municípios brasileiros nos Jogos.

A dicotomia na competição e educação esteve presente nos debates da área da Educação Física na década de 1980 (BRACHT, 2001) e está claramente manifestada nos discursos dos gestores das duas primeiras fases dos jogos. Segundo Hungaro (2011, p. 137), nos anos 80 a Educação Física brasileira deu início a um profundo processo de autocrítica, estimulando na área um "teorizar crítico" que apresentava uma marca bem definida: "o ponto de vista dos

\footnotetext{
1 Coordenador Geral dos Jogos Escolares na primeira fase

2 Secretário Nacional de Esporte na primeira fase

3 Coordenador Geral dos Jogos Escolares - entrevistado "a" na segunda fase

4 Coordenador Geral dos Jogos Escolares - entrevistado "b" na segunda fase
} 
de baixo". O autor ainda afirma que a "interlocução com a teoria social de Marx foi fundamental para a construção de um projeto de interrupção de ruptura da educação física".

Se na primeira fase havia o desejo da busca de talentos e da formação de atletas olímpicos, na segunda a ideia forte era a do Desporto Educacional, definido por Tubino (2010, p. 85) como o esporte no qual deve ser evitada "a seletividade e a hipercompetitividade", e também de rompimento com o Esporte de Rendimento. Isto é demonstrado pela decisão do Secretário de Esporte, à época Bruno da Silveira, proibindo a participação de atletas federados entre os anos 1985 e 1987. Tal decisão tem consequência imediata: a queda do nível técnico da competição, demonstrada por Ferreira (1992), evidenciando que os resultados do atletismo no JEBs entre 1985 e 1987 são de qualidade técnica inferior aos encontrados entre os anos de 1980 e 1984.

Segundo Hungaro (2011, p. 144), os anos 1990 fizeram com que o projeto progressista da educação física fosse interrompido pela chamada crise dos paradigmas: "Tal projeto, inaugurado nos anos 80, fortalecido até meados dos anos 90, começa a se defrontar com um contexto pós moderno extremamente conservador (em certo sentido, inclusive, reacionário) e absolutamente avesso ao marxismo - que tanto inspirou o projeto de intenção de ruptura". Na terceira fase, a busca de talentos é retomada, mas é possível identificar um conflito de visões dentro do próprio Instituto Nacional do Desenvolvimento do Desporto (INDESP), como destacado neste trecho da entrevista com SNEa- $3^{5}$ :

\footnotetext{
"Mantivemos a Olimpíada Colegial Esperança sub-quatorze mais um enfoque participativo e na valorização da presença da escola, e como quinze a dezessete... Fezse os Jogos da Juventude com mais ênfase à competição ao Esporte de Rendimento..."
}

Abaixo, é possível perceber na fala de SNEa-3 uma preocupação em não submeter o esporte escolar às necessidades do Esporte de Rendimento. Essa visão se alinha à preocupação de Pires (2001), de "não subordinação às necessidades do esporte federado", mesmo entendendo a ligação que existe entre ambos.

SNEa-3: "Nos Jogos da Juventude havia um motivo da sua existência que era o esporte da juventude de alto rendimento, mas era necessário resgatar o papel do esporte na escola."

Com relação aos Jogos da Juventude vale destacar, segundo CGb-2, seu surgimento como uma resposta da área esportiva para o desenvolvimento do Esporte de Rendimento. Porém, com os Jogos da Juventude, MIN-4 acaba afirmando que o fato de não terem como base a escola trazia, na verdade, pouca contribuição ao desenvolvimento esportivo.

Na quarta fase (2005-2010) não se percebe mais este conflito relacionado à orientação dos Jogos, mas surge uma visão de integração dessas perspectivas, anteriormente antagônicas. A percepção dos gestores dessa fase avançou para a questão da dimensão dos jogos, como se observa abaixo:

CG-46: "os grandes resultados começam a aparecer, porque você começa ter mais gente entrando na base, você começa a ter mais pessoas de alto nível querendo disputar, porque você tem uma bolsa atleta, você tem uma bolsa na escola".

5 Secretário Nacional de Esporte entrevistado "a" na terceira fase
6 Coordenador Geral dos jogos escolares na quarta fase. 
MIN-47: "o governo deveria fazer um evento nacional, estimular os eventos estaduais e que dialogasse com as escolas e que cada escola e cada município participassem das etapas municipais, estaduais e nacional. Com isso você mobiliza uma engrenagem e milhões de pessoas participando."

Passada pouco mais de uma década, Tubino (2010) revê a posição sobre o Desporto Educacional manifestada em Tubino (1996) e apresenta um novo conceito: "o EsporteEducação é uma das formas de exercício do direto de todos às práticas esportivas. É dividido em Esporte Educacional (para todos na escola) e Esporte Escolar (para aqueles com mais vocações e possibilidades esportivas)" (TUBINO, 2010, p. 122). É importante observar que este entendimento de Tubino (2010) do binômio Esporte-Educação é diferente e mais amplo do que o tratamento dado ao Desporto Educacional (Tubino, 1996). No conceito "antigo" de Desporto Educacional, só existe referência ao esporte que "evita a seletividade" e é "orientado para a prática do lazer", portanto, sem fazer referência ao Esporte Escolar e às competições escolares. É pelo Esporte Escolar (rendimento na escola), que os jogos escolares se articulam com o binômio EsporteEducação.

Segundo Pires (2003, p. 76), "a filosofia organiza um conjunto de valores partilhados, que traduzidos nas normas de comportamento determinam a identidade cultural de uma organização". Ou seja, cada período dos jogos tinha seu "conjunto de valores" e foi isto que deu a identidade a esses períodos. A acentuada diferença entre os dois primeiros períodos dos jogos foi marcada pela dicotomia Esporte de Rendimento e Desporto Educacional e determinou o perfil de cada um.

Para Lewis e Appenzeller (1985), a filosofia e a política são o ponto inicial para a organização de qualquer processo. A filosofia deixa claro o papel pretendido e a política providencia as linhas para as ações práticas. A filosofia pode dar base para o gestor formular novas respostas e assim posicionar sua organização de uma melhor maneira, como propõe Mintzberg (1990).

Na primeira fase (1969-1984) a competição teve maior ênfase e foi esse aspecto que acabou por caracterizá-la. Porém, existem passagens importantes que demonstram o caráter educacional dessa fase, como quando o entrevistado CG-1 relata a expulsão do técnico Kanela (bicampeão Mundial e medalhista Olímpico de Basquete) por considerar que a postura dele não estava condizente com o papel educacional dos Jogos. Na segunda fase (1985-1989) a ênfase do discurso foi educacional, porém notou-se que também existiu competição, cuja diferença estava na qualidade do nível técnico dos resultados esportivos, que foram inferiores aos da primeira fase, como citado por Ferreira (1992).

Já na terceira fase (1990 a 2004) existiu uma tentativa de separar estes dois elementos, criando eventos diferenciados: Jogos da Juventude, com ênfase na competição e rendimento esportivo, e Olimpíadas Colegiais da Esperança e JEB's, cuja ênfase situava-se nos aspectos educacionais. $\mathrm{O}$ que efetivamente aconteceu foi que ambos os eventos continham elementos de competição e educacionais em níveis diferenciados. Na quarta fase, já com a nova nomenclatura Olimpíada Escolar, o discurso foi relativo à convivência entre aspectos de competição e educacionais, orientando o evento para o desenvolvimento integral do aluno e também para a descoberta dos talentos esportivos.

A quarta fase (2005-2010) é a que encontra maior afinidade "ideológica" com os modelos pedagógicos para o esporte na escola, que podem ser percebidos em Kirk (2013), Siedentop et al. (2011), Côte et al. (2012), Kirk e Gorely (2000), no que tange à pluralidade e à não aceitação de uma dicotomia artificial.

7 Ministro do Esporte na quarta fase. 


\section{Papel dos atores}

Observa-se nos relatos que há participação dos vários níveis de governos - federal, estadual e municipal -, de entidades privadas e indivíduos (técnicos e atletas escolares). Estes diversos atores estão conectados por diferentes papéis que se complementam para a execução dos jogos. Na primeira fase dos Jogos, em que a organização do evento ainda se estruturava, a temática recorrente ligava-se ao micronível, como se observa abaixo:

CG-1: "O técnico hoje é igual da minha época. O técnico é quem vai buscar o atleta lá na competição. (...) O que acontece nesses colégios particulares, dão bolsa de estudo para os melhores atletas, e era uma propaganda danada para o colégio".

Um detalhe interessante da segunda fase (1984 a 1989) foi o fato de a União Brasileira de Estudantes Secundaristas (UBES) ser convidada para fazer parte da comissão organizadora dos jogos, pois, segundo CGa-2, acreditava-se que "os alunos eram protagonistas dos jogos, tinham que estar juntos na organização". Por sua vez, CGb-2 afirma o seguinte: “...quem tinha que estar discutindo a questão do Esporte Escolar e do Esporte Educacional era a Secretaria de Educação e não a Secretaria de Esporte".

Essa discussão a respeito do responsável pelo Esporte Escolar ainda existe entre as áreas da Educação e do Esporte e não é um problema apenas do Brasil. Segundo Sarmento (2002), em Portugal também existe uma falta de coordenação entre os setores da Educação e do Esporte. De forma distinta, no relatório do Sport NI (2012), na Irlanda do Norte, a escola é considerada como integrante do sistema de esporte e é responsável pelo contato inicial da criança com o esporte.

No Brasil, esse conflito está vinculado, em certa medida, ao fato de que todas as questões relativas ao esporte brasileiro funcionaram dentro do MEC por várias décadas. Soma-se a esse fato a criação de um Ministério específico para o Esporte apenas em 2003, justificando as dificuldades existentes a respeito dos limites da atuação de cada uma das áreas.

Esse é um dos grandes conflitos que os gestores dessa área necessitam gerir, pois, segundo Mintzberg (1990), a gestão de conflitos é prerrogativa do cargo. De Bosscher (2009) e Green e Oakley (2001) chamam atenção para a importância da organização política e estrutura esportiva do país, e também da clara definição do papel de cada ator para que se atinja o sucesso esportivo. Uma estrutura inadequada, lenta e inoperante, assim como a indefinição de papéis, contribui para o insucesso esportivo.

Na terceira fase (1990-2004), questões relativas às subcategorias do mesonível ficam aparentes na discussão do papel mobilizador das Secretarias de Esporte, como se vê abaixo:

SNEa-3: "Uma função muito importante desempenhada pelas Secretarias Estaduais de Esporte é a mobilização das Secretarias Municipais de Esporte..."

Gestores da quarta fase (2005-2010) destacam o papel do Ministério do Esporte como articulador dos demais atores:

CG-4: "Eu acho que esse é o grande papel do Ministério do Esporte, articular as ações dos demais ministérios para poder, eles contribuírem no projeto..."

MIN-4: "Ministério não sai lá para entrar na Secretaria de Esporte de um determinado município e dizer o que ele vai fazer." 
A articulação entre o Ministério do Esporte e seus pares públicos (Secretarias Estaduais e Municipais de Esporte e também o Comitê Olímpico Brasileiro) para um projeto de desenvolvimento do esporte é o esperado por Kirk e Gorely (2000), quando falam da importância de uma política inteligente em seu Modelo Inclusivo. Segundo Mintzberg (1990), negociar os limites de atuação de cada instituição é importante. Para o sucesso na organização dos jogos escolares, os gestores públicos e privados necessitam estar atentos a esta tarefa. Para cada nível de atuação existe também um papel a ser cumprido por cada ator do sistema. Entender como essas relações interagem é importante para o funcionamento de todo o sistema. Porém, segundo Pires, Colaço e Sarmento (2004), o que se percebe é que os atores do sistema esportivo desenvolvem políticas que não se articulam. Sarmento (1999) destaca a importância de que todos intervenientes do sistema esportivo estejam articulados e com papéis bem definidos.

Segundo Mintzberg (1999), uma organização tem cinco componentes básicos para o seu funcionamento: o vértice estratégico, a linha hierárquica e o centro operacional, além da tecnoestrutura e do pessoal de apoio. Propomos olhar para os Jogos Escolares Brasileiros como produto de uma organização que também tem seus componentes básicos para o funcionamento, bem como atores responsáveis por cada uma destas unidades.

Assim, simplificando a representação proposta por Mintzberg (1999), vamos nos fixar em três componentes básicos apontados por esse autor: vértice estratégico, linha hierárquica e centro operacional, e relacioná-los às subcategorias propostas anteriormente: macronível, mesonível e micronível. A relação fica assim estabelecida:

1. Vértice estratégico e macronível, onde atuam os Organismos Nacionais públicos e os privados;

2. Linha hierárquica e mesonível, compreendendo os Organismos públicos e privados que atuam a nível Estadual;

3. Centro operacional e micronível, com participação de estruturas onde ocorrem a preparação esportiva e jogos, e pessoas que atuam na operacionalização do evento.

É certo que os organismos públicos e privados diferem quanto às possibilidades, pois, se no caso dos privados é clara a subordinação hierárquica e apoio entre si, no caso dos públicos o mesmo não acontece, já que a legislação brasileira (BRASIL, 1988; BRASIL, 1998) assegura autonomia e não subordinação dos diferentes níveis de governo. Entretanto, há que se admitir que os organismos públicos nacionais podem, por meio de uma política clara e sustentada pelo financiamento federal, conseguir adesão e apoio dos segmentos estaduais e municipais. Cumprem, então, o papel que lhe cabe de fomentadora. Feitas essas considerações e percebidas as diferenças, é possível supor que o modelo proposto por Mintzberg (1999), com as simplificações já observadas, espelha, de certa maneira, a forma como o processo todo pode estar atrelado.

\section{Financiamento}

Embora seja esperado que o financiamento dos Jogos seja público, foi importante identificar de que forma isto se deu e por meio de que fontes ocorreu. No Ministério do Esporte e COB há um entendimento antagônico sobre o financiamento dos Jogos, relativo principalmente à quarta fase dos Jogos. Enquanto o COB afirma que são os financiadores dos Jogos, o Ministério do Esporte afirma o contrário, que o financiamento dos Jogos foi sempre público.

Percebe-se pelos relatos que recursos públicos que sustentaram os Jogos ao longo de sua existência, iniciada em 1969, fizeram um caminho inicial pelo financiamento dos recursos provenientes das rubricas orçamentárias (principalmente no primeiro e segundo período dos 
jogos), passando pelo financiamento das estatais em alguma medida no terceiro período, até a solução atual de recursos financeiros provenientes de Lei Federal na quarta fase.

Abaixo, os entrevistados manifestam a clara dependência dos recursos públicos para a realização dos Jogos nas quatro fases:

CG-1: "Os Estados, alguns a gente ajudava".

SNE-1: "As verbas, a execução desses eventos, eram todas elas exclusivamente da SEED".

CGa-2: “... você parte de um momento em que você dependia do orçamento público".

CGb-2: "Tudo que se fazia (pagava) no país, em termo de esporte, saía da SE$E D / M E C$ ".

SNEb-3: "Era uma coisa que primeiro não tinha divulgação, era custeada pelo SEED/MEC. ..." "então a minha ideia foi buscar junto ao presidente essa situação de recurso nas estatais que passaram a investir".

SNEa-3: "Então ficou na verdade a obrigação (financeira) para cima do INDESP".

CG-4: "Lei Agnelo/Piva, pensando nisso teve a preocupação em destinar um recurso específico para o Esporte Escolar".

MIN-4: "Então nós fizemos uma novidade e o pulo do gato foi justamente isso, tirando $2 \%$ de todas as loterias federais, do prêmio".

Grix e Phillpots (2011) afirmam que o financiamento do esporte no Reino Unido (UK) é proveniente do governo, que por isso também dita a estratégia do desenvolvimento do esporte de base e de elite, cabendo aos demais parceiros o papel de operacionalização da política proposta. De Bosscher (2009), em seu modelo de nove pilares para a política de Esporte de Rendimento, trata o financiamento como um pilar fundamental, que se relaciona com a entrada (input). Isto é, é importante ter recursos financeiros, mas como é possível perceber pela recente história dos Jogos, é necessária também uma forma estável de financiamento, como a que ocorreu na quarta fase.

\section{Perspectivas futuras}

Abaixo, gestores da primeira (1969-1984) e terceira (1990-2004) fase chamam atenção para a governança dos Jogos, manifestando a opinião de que existe uma parceria importante, mas cada um deve ter um papel bem definido: ao poder público, financiamento e determinação da linha estratégica a seguir, ao COB o papel de operacionalização do evento, como se verifica abaixo:

CG-1: "Eu achava que esses jogos iam continuar dentro do MEC... o COB não tem nada com isso".

SNEa-3: “... essa competição ser promovida pelo Ministério do Esporte sim, com a intervenção técnica do COB...”.

Gestor da segunda fase (1985-1989) destaca a importância dos Jogos serem inclusivos, assimilando os deficientes: 
CGa-2: "Eu acho que Esporte Escolar deveria ficar centrado exclusivamente nas modalidades que você pode desenvolver, a partir da escola... a partir da escola $e$ incluindo todos os alunos, inclusive os com deficiência".

Já os gestores da terceira (1990-2004) e quarta fase (2005-2010) desejam a ampliação do número de estudantes, escolas e municípios:

SNEa-3: “...sonhar que $80 \%$ de todas as escolas do Brasil participem”.

CG-4: “... ter todos os municípios, ter um número, vou colocar aqui, setenta mil escolas no Brasil participando".

MIN-4: “... ser universal”.

Eles destacam a preocupação com a governança dos Jogos entre CG-1 e SNEa-3 e cobram uma retomada da governança pelo órgão público responsável pelo Esporte Escolar. Não é à toa que fazem isto, pois sabem, como Druker (1997), que o papel do gestor é de liderança, portanto, deve conduzir à organização para os objetivos pretendidos. No caso específico de uma organização como o Ministério do Esporte (que é pública), Druker (1997) aponta a necessidade de produzir mudanças nos indivíduos e na sociedade.

Para Grixx e Phillpots (2011), os esforços para ampliação da base esportiva e o desenvolvimento de caminhos para o Esporte de Rendimento, via descoberta e promoção de talentos, foram consolidados com a forte presença do governo britânico. O papel do governante foi decisivo na tomada de decisões estratégicas para o desenvolvimento do esporte. Neste sentido, o fato de a governança dos Jogos não estar unida aos Ministérios do Esporte e Educação atrasa a consolidação desse caminho para a descoberta e promoção de talentos. De Bosscher (2009) apresenta o aumento da participação como um dos pilares de sucesso do Esporte de Rendimento, e as competições escolares como um dos fatores importantes para tal.

O relatório do TCU (2011) destaca que o sucesso na identificação de talentos esportivos depende de políticas capazes de permitir o acesso a um grande contingente de crianças e jovens, a iniciação esportiva. Observou-se que as escolas públicas brasileiras estão desvinculadas da iniciação esportiva. Por um lado, a Educação Física não enfatiza a prática esportiva e, por outro, no contraturno escolar praticamente não há espaço para o treinamento esportivo.

Segundo Dennis e Grix (2012), as Spartakiades foram consideradas a base do sucesso do Esporte de Rendimento na Alemanha Oriental. Este sistema de captação e mobilização de um grande contingente de jovens em várias etapas provou ser bem-sucedido para formação de atletas. Diversos atletas de destaque internacional obtiveram suas primeiras vitórias nesses eventos.

A ampliação da participação das escolas e etapas municipais de seleção, como sugerem SNEa-3 e CG-4, ou mesmo a universalização da participação, como quer MIN-4, o caráter educacional combinado com o de rendimento e a participação de atletas com deficiência integrados aos jogos escolares, como sugere $\mathrm{CGa}-2$, são mudanças importantes que devem ter o apoio da administração pública. Como indicam Sarmento e Pires (2004), resultados inovadores são frutos de soluções diferentes para velhos problemas.

No entanto, para que essas mudanças aconteçam na proporção e dimensão que querem os gestores de esporte entrevistados, esse processo deve ser assumido pelos Ministérios do Esporte e da Educação, liderando em conjunto e inspirando seus parceiros públicos e privados a trabalharem no sentido de universalizar o acesso às competições escolares. Segundo Mintzberg $(1990 ; 1996 ; 1998)$, a inspiração deve ser elemento fundamental no papel do gestor em- 
preendedor, que mantém sua liderança de forma compatível com o modelo normativo de controle e se expressa com a mesma suavidade de um maestro de orquestra sinfônica.

\section{Conclusões}

De acordo com as entrevistas realizadas, o que se percebe é que, nas quatro fases, independentemente da ênfase da opinião, sempre existiram aspectos relacionados à competição e ao Esporte Educacional que não devem ser ignorados. A diferença entre as fases ocorreu, mas não em função da presença ou da falta desses aspectos e sim da predominância de um sobre o outro.

Fica nítida a busca de talentos para o esporte nacional em todas as fases, à exceção da segunda (1984 a 1989), na qual houve um movimento de distanciamento do Esporte de Rendimento, explicitado pelo banimento dos atletas federados das competições escolares e também pelo decréscimo da qualidade do resultado esportivo. Na quarta fase (2005-2010) dos Jogos, conhecida por Olimpíada Escolar, procurou-se a convivência harmônica entre aspectos de competição e educacionais, representando o amadurecimento dos Jogos, calcados nas experiências anteriores que ajudaram a compor este novo perfil.

Quanto aos atores, observa-se que há a participação dos vários níveis de governos federal, estadual e municipal - entidades privadas e indivíduos (técnicos e atletas escolares). Esses diversos atores estão conectados por diferentes papéis que se complementam para a execução dos jogos. Apesar da garantia constitucional da não subordinação dos entes federativos (no caso das entidades públicas), o fato é que organismos públicos nacionais podem, por meio de uma política clara e sustentada pelo financiamento federal, conseguir adesão e apoio dos segmentos estaduais e municipais, cumprindo, assim, o papel que lhes cabe de fomentadores.

Os recursos públicos que sustentaram os Jogos Escolares Brasileiros ao longo dos 41 anos fizeram um caminho inicial pelo financiamento de recursos provenientes das rubricas orçamentárias (principalmente na primeira e segunda fase dos Jogos), passando pelo financiamento das estatais, em alguma medida, na terceira fase, até a solução atual de recursos financeiros provenientes de Lei Federal na quarta fase.

Essa solução encontrada para o financiamento dos Jogos na quarta fase teve efeitos colaterais. O principal foi o fortalecimento da presença do COB e o enfraquecimento da presença governamental nesse evento, pois os recursos dessa lei vão direto dos cofres públicos para o COB, diminuindo, ou mesmo aniquilando, a decisão do Ministério do Esporte quanto a sua utilização. A retomada da governança dos Jogos pelos Ministérios do Esporte e da Educação é de fundamental importância para ampliar a participação nesse evento. A "universalização" dos Jogos está diretamente ligada à capacidade do poder público em incentivar seus parceiros e disponibilizar os meios para isso.

Apesar do quadro histórico traçado, reconhecemos que ainda são necessárias novas informações para uma análise mais aprofundada. Nesse sentido, sugerimos entrevista com outros atores dos Jogos, como atletas escolares, técnicos e chefes de delegação.

\section{Referências}

APPENZELLER, H.; LEWIS, G. Successful sport management. Carolina Academic Press, 2000 .

ARANTES, A. A. C.; SILVA, F. M.; SARMENTO, J. P. Jogos Escolares Brasileiros: Reconstrução histórica. Revista Motricidade, v. 8, n. 2, p. 916-924, 2012. 
BARBIERI, C. Educação pelo esporte: algumas considerações para a realização dos Jogos do Esporte Educacional. Movimento, Porto Alegre, v. 5, n. 11, 1999. Disponível em: http://www.seer.ufrgs.br/index.php/Movimento/article/view/2481/1131. Acesso em: 4 out. 2016.

BARDIN, L. Análise de conteúdo. Lisboa: Edições, 1994.

BORGES, E. C.; BUORICORE, A. C. Memórias do esporte educacional brasileiro: Breve história dos jogos universitários e escolares. São Paulo: Centro de Estudos e Memória da Juventude, 2007.

BRACHT, V. Esporte na escola e esporte de rendimento. Revista Movimento, v. 1, n. 12, p. 14-19, 2001.

BRASIL. Lei n. 10.264 de 16 de julho de 2001 (Lei Agnelo Piva). Diário Oficial da União, 17.07.2001. Brasília: Poder Executivo.

BRASIL. Constituição (1988). Constituição da República Federativa do Brasil. Brasília, DF: Senado Federal: Centro Gráfico, 1988. 292 p.

BRASIL. Lei n. 9615 de 24 de março de 1998. Institui normas gerais sobre desporto e dá outras providências (Lei Pelé). Diário Oficial da União, 25.03.1998. Brasília: Poder Executivo. COB. Dossiê de Candidatura do Rio de Janeiro a sede dos Jogos Olímpicos e Paraolímpicos de 2016. Rio de Janeiro. 2009.

DE BOSSCHER, V.; DE KNOP, P.; VAN BOTTENBURG, M.; SHIBLI, S.; BINGHAM, J. Explaining international sporting success: An international comparison of elite sport systems and policies in six countries. Sport Management Review, v. 12, n. 3, p. 113-136, 2009.

DENNIS, M.; GRIX, J. Finding and Promoting Young Sporting Talent. In: DENNIS, M.; GRIX, J. Sport Under Communism. London: Palgrave Macmillan. 2012. p. 56-82.

DRUCKER, P. F. As organizações sem fins lucrativos. Lisboa: Difusão Cultural. 1997.

FERREIRA, F. F. Atletismo jogos e campeonatos escolares brasileiros 1980\1990. Dados estatísticos e informativos. Brasília, 1992.

FRIZZO, G. Os jogos escolares como mecanismos de manutenção e eliminação: uma crítica à lógica esportiva na escola. Movimento, Porto Alegre, v. 19, n. 04, p. 163-180, 2013. Disponível em: http://www.seer.ufrgs.br/index.php/Movimento/article/view/38628/27449. Acesso em: 20 out. 2016.

GHIGLIONE, R.; MATALON, B. O Inquérito: teoria e prática. Oeiras: Celta, 2005.

GREEN, M.; OAKLEY, B. Elite sport development systems and playing to win: uniformity and diversity in international approaches. Leisure Studies, v. 20, n. 4, p. 247-276, 2001.

GRIX, J.; PHILLPOTS, L. Revisiting the 'governance narrative' 'Asymmetrical network governance' and the deviant case of the sports policy sector. Public policy and administration, v. 26, n. 1, p. 3-19. 2011. 
GRUPPI, D. R. Trajetórias dos jogos escolares brasileiros para os jogos dos povos indígenas. Revista Internacional de Ciencias Sociales de la Actividad Física, el Juego y el Deporte, v. $10, \quad$ n. $10,2016.2$ Disponível https://dialnet.unirioja.es/servlet/articulo?codigo=5593507.

HUNGARO. "A educação física e a tentativa de "deixar de mentir": o projeto de "intenção de ruptura". In: Medina, J.P. (Org.). A educação física cuida do corpo... e mente. Novas contradições e desafios do século XXI. 25 ed. Campinas, Papirus. (p. 135-159).

KIOURANIS, T. D. S. Os jogos escolares brasileiros chegam ao século XXI: reprodução ou modernização na política de esporte escolar? Tese (Doutorado em Educação Física) - Faculdade de Educação Física, Universidade Federal do Paraná. Curitiba, 2017.

KIRK, D. Educational value and models-based practice in physical education. Educational Philosophy and Theory, v. 45, n. 9, p. 973-986. 2013.

KIRK, D.; GORELY, T. Challenging thinking about the relationship between school physical education and sport performance. European Physical Education Review, v. 6, n. 2, p. 119$143,2000$.

MEIRA, B. T.; BASTOS, F. C. Esporte infanto juvenil: treinamento em longo prazo. Estrutura de organização e de promoção esportiva. São Paulo: Phorte. 2011.

MINTZBER, H. Covert leadership: notes on managing professionals. Harvard Business Review, v. 76, n. 6, p. 140-147, 1998.

MINTZBERG, H. Estrutura e dinâmica das organizações. Lisboa: Publicações Dom Quixote, 1999.

MINTZBERG, H. Managing government, governing managing. Harvard Business Review, v. 74, n. 3, p. 75-83, 1996.

MINTZBERG, H. The manager's job: folklore and fact. Harvard Business Review, v. 68, n. 2, p. 163-176, 1990.

MINTZBERG, H. The nature of managerial work. New York: Harper \& Row, 1973.

OLIVEIRA, F. S. Jogos escolares: possíveis influências na prática pedagógica das aulas de educação física escolar. EFDeportes.com, Buenos Aires, v. 16, n. 161, 2011.

Disponível em: http://www.efdeportes.com/efd161/jogos-escolares-influencias-na-praticapedagogica.htm. Acesso em: 20 out. 2016.

PIRES, G. Da educação física ao alto rendimento: a coragem de dar um passo no desconhecido. In: BENTO, J. O; PIRES, G.; SOUSA, G.; MEIRIM, J. Da educação física ao alto rendimento. Madeira: Universidade da Madeira. p. 27-72, 2001.

PIRES, G. Gestão do Desporto: desenvolvimento organizacional. Porto: APOGESD, 2003.

PIRES, G.; MATIELLO JUNIOR, E.; GONÇALVES, A. Lazer: um princípio para a educação física curricular universitária. Movimento, v. 5, n. 11, p. 74-84, 1999. 
PIRES, G.; COLAÇO, C.; SARMENTO, J. P. Desporto e Desenvolvimento. Povos e Culturas - No 9 Cultura e Desporto. Lisboa: Centro de Estudos dos Povos e Culturas de Expressão Portuguesa, Universidade Católica Portuguesa. 2004. p. 335-357.

SARMENTO, J. P. Desporto universitário? Porto: Edição Associação de Estudantes da FCDEF-UP, 2002.

SARMENTO, J. P.; PIRES, G. Gestão do Desporto: novos desafios, diferentes soluções. Povos e Culturas - No 9 Cultura e Desporto. Lisboa: Centro de Estudos dos Povos e Culturas de Expressão Portuguesa, Universidade Católica Portuguesa. 2004. p. 407-430.

SARMENTO, P.; BASTOS, F.; LUGUETTI, C. A sustentabilidade dos sistemas desportivos e o desporto na escola. In: MESQUITA, I.; BENTO, J. (Eds.). Professor de Educação Física: fundar e dignificar a profissão. Belo Horizonte: Casa da Educação Física, p. 301-323, 2012 .

SPORT NI. Sport Policy Factors Leading to International Sporting Success: An audit of the elite sport development system in Northern Ireland. Belfast: Sport Northern Ireland. 2012. Disponível em: http://www.sportni.net/sportni/wp content/uploads/2013/07/Splissreducedwebversion.pdf. Acesso em: 06 dez. 2017

SIEDENTOP, D.; HASTIE, P.; MARS, H. Complete Guide to Sport Education. 2. ed. Champaign: Human Kinetics. 2011.

TCU. Relatório de Auditoria Operacional: Esporte de Alto Rendimento. Brasília, DF, 2011. THOMPSON, I.; AMARAL W. J.; GARCIA C. A.; MORAES R. M. Esporte Estudantil Brasileiro. In: DACOSTA, L. P. (Ed.). Atlas do Esporte no Brasil. Rio de Janeiro: Shape, p. 809-811, 2001.

TRIVINOS, A. N. S. Introdução à pesquisa em ciências sociais: a pesquisa qualitativa em educação. São Paulo: Atlas, 1987.

TUBINO, M. J. G. Estudos brasileiros sobre o esporte: ênfase no esporte-educação. Maringá: EDUEM, 2010.

TUBINO, M. J. G. (org.). Repensando o esporte brasileiro. São Paulo: Ibrasa, 1996.

Recebido em: 04/11/2018

Revisado em: 30/12/2018

Aprovado em: 30/12/2018

Endereço para correspondência:

andrealmeida1965@outlook.com

Andre Almeida Cunha Arantes

Universidade Católica de Brasília

Faculdade de Educação Física

Câmpus Taguatinga

QS 07 Lote 01 - EPCT

71966-700 - Taguatinga, Brasília/DF - 